УДК 678.652:66.022.32

\title{
T.Э. Рымар
}

\section{ВЛИЯНИЕ МИНЕРАЛЬНЫХ ДОБАВОК НА ПРОЦЕСС ФОРМИРОВАНИЯ ПОРИСТОЙ СТРУКТУРЫ ЖИДКОСТЕКОЛЬНЫХ ЗЕРНИСТЫХ ТЕПЛОИЗОЛЯЦИОННЫХ МАТЕРИАЛОВ}

\author{
Восточноукраинский национальный университет имени Владимира Даля, г. Северодонецк
}

\begin{abstract}
Изучено влияние минеральных добавок на процесс формирования пористой структуры жидкостекольных зернистых теплоизоляционных материалов. Для регулирования реологических характеристик сырьевой смеси и эксплуатационных свойств вспученных материалов при производстве зернистых утеплителей на основе жидкостекольных композиций (ЖСК) вводились тонкомолотые минеральные наполнители: каолин, доломитовая мука, оксид железа(III), оксид цинка, карбонат кальция. Установлено, что применение наполнителя оксида цинка в количестве 1,5 мас.ч на 100 мас.ч жидкого стекла при изготовлении гранулированного материала является наиболее оптимальным, так как данный наполнитель придает вспученному грануляту низкий показатель плотности, а также высокую способность к вспучиванию, о чем свидетельствует высокое значение степени перестройки структуры $(0,64)$. Строго дозированное содержание оксида цинка позволяет упростить гранулирование исходной ЖСК через фильерную пластину, так как скорость истечения этой смеси по сравнению с чистым жидким стеклом (31 с) увеличилась вдвое (69 с). При этом поризационная способность композиции не падает, так как количество удаленной при вспучивании влаги составляет $25,3 \%$, что выше, чем количество удаленной влаги при вспучивании гранул, изготовленных только из жидкого стекла (20,7\%). Таким образом, содержание оксида цинка в ЖСК в количестве 1,5 мас.ч привело к созданию в структуре гранулы достаточного количества твердой фазы без разрушения структуры молекулы жидкого стекла и перехода связанной воды в свободную.
\end{abstract}

Ключевые слова: минеральные добавки, наполнители, зернистый теплоизоляционный материал, жидкостекольные композиции, пористая структура, вспучивание, вязкость, фазовый состав.

DOI: $10.32434 / 0321-4095-2019-123-2-112-120$

\section{Введение}

В настоящее время к эффективным теплоизоляционным материалам относят утеплители, имеющие теплопроводность не выше 0,06 Вт/(м. $\left.{ }^{0} \mathrm{C}\right)$. Данные материалы должны характеризоваться доступностью сырья, малой энергоемкостью и низкой себестоимостью производства, обладать водо- и морозостойкостью, механической прочностью, экологической и пожарной безопасностью [1].

Специфика пористой структуры (преобладание закрытой пористости; наличие межзерновых пустот, также являющихся порами неопределенной формы) обусловливает не только хо- рошие теплотехнические свойства зернистых теплоизоляционных материалов, но и стабильность показателей их качества в целом. Все эти факторы свидетельствуют о перспективности применения данного вида утеплителей для устройства современной энергоэффективной тепловой защиты зданий и сооружений [2].

Теплопроводность и строительно-эксплуатационные свойства утеплителей, в том числе и зернистых, в решающей мере зависят от объема пористости, характера пористой структуры, характеристик пор и твердой фазы. Наиболее широкие возможности регулирования пористой структуры наблюдаются у зернистых теплоизо-

(C) Т.Э. Рымар, 2019 
ляционных материалов на основе вспученного жидкого стекла (жидкостекольной композиции, ЖСК), что обусловлено спецификой свойств последнего [3].

Гранулированный полуфабрикат на основе жидкого стекла предварительно готовят путем коагуляции натриевого жидкого стекла в среде раствора хлорида кальция $\left(\mathrm{CaCl}_{2}\right)$. При добавлении жидкого стекла распылением с помощью сжатого воздуха в концентрированный раствор $\mathrm{CaCl}_{2}$, на границе двух жидких фаз преобладает реакция гидролиза из-за разницы $\mathrm{pH}$ растворов. Нейтрализация заряда анионов приводит к немедленной коагуляции поверхностных связей. Если концентрация силикатов достаточно высока, образуется мембрана с отрицательным зарядом со стороны силиката и с положительным зарядом со стороны раствора хлорида кальция. Когда вязкость силикатного раствора высока, мембрана постепенно трансформируется в гелеобразную оболочку с коагулированным силикатом с градиентом низкой концентрации, создаваемого стенками кальция из раствора $\mathrm{CaCl}_{2}$ и натрием из раствора силиката. После сушки поверхности влажных гранул, полученных из капель жидкого стекла, которые изготовленные с водостойкой поверхностью, образуется частично кальцинированный слой, который не является паро- и влагостойким (вследствие образования микротрещин при усадке) $[4]$.

Процесс вспучивания предварительно отформованных гранул широко применяется для получения эффективных зернистых теплоизоляционных материалов. Вспучиванием называют процесс увеличения объема зерен материала при термообработке, сопровождающийся образованием высокопористой внутренней структуры с преобладанием закрытых пор. Процесс вспучивания жидкостекольной гранулы включает следующие два этапа: 1 - образование газонепроницаемой оболочки в вязкопластическом состоянии из жидкого стекла; 2 - вспучивание под давлением водяных паров, образующихся внутри зерен в процессе удаления воды при переходе жидкого стекла в пиропластическое состояние [5].

Для регулирования реологических характеристик сырьевой смеси и строительно-эксплуатационных свойств вспученных материалов при производстве зернистых утеплителей на основе жидкого стекла и жидкостекольных композиций вводят тонкомолотые минеральные наполнители и модифицирующие добавки.
Целью данной работы является изучение влияния различных минеральных добавок на процесс формирования пористой структуры жидкостекольных зернистых теплоизоляционных материалов.

\section{Экспериментальная часть}

В качестве минеральных добавок были использованы: каолин, доломитовая мука, оксид железа(III), оксид цинка, карбонат кальция.

Взаимодействие растворов щелочных силикатов с растворимыми соединениями поливалентных металлов, таких как цинк, кадмий, медь, никель, железо, марганец, свинец и другие, во многом протекает аналогично взаимодействию с солями щелочноземельных металлов. Образование студенистых осадков малорастворимых гидроксидов металлов происходит легко и способствует созданию мембран на границах смешиваемых фаз. Образование кристаллических продуктов при этом также маловероятно. В местах контакта фаз рН резко изменяется, так как ионы гидроксида поглощаются катионами поливалентного металла, что способствует полимеризации кремнезема. Поверхность студенистых осадков более развита и склонна к адсорбции и соосаждению различных ионов. Продукты взаимодействия представляют собой смесь гидроксидов, силикатов и основных солей в аморфном состоянии, соотношение между ними определяется условиями проведения реакции. Что касается оксида цинка, то он осаждает кремнезем из растворов жидких стекол.

Жидкое стекло вследствие высокой дисперсности его твердой фазы находится в метастабильном, неустойчивом состоянии и любые внешние энергетические воздействия вызывают достаточно сильные изменения его состава и свойств, вплоть до полного разрушения и деградации. Минеральные наполнители или добавки химических веществ, используемые при приготовлении ЖСК, вызывают индивидуальную реакцию жидкого стекла на каждую вводимую добавку. Тонкодисперсные минеральные наполнители, вводимые в состав ЖСК в количестве более 8-10 мас.\%, адсорбируя на своей поверхности ионы жидкого стекла или связывая диполи свободной воды, вызывают либо гелеобразование в жидком стекле, либо разжижение смеси [6]. Все эти факторы значительно влияют на способность ЖСК к вспучиванию.

На процесс формирования пористой структуры жидкостекольных зернистых материалов значительное влияние оказывают такие характеристики как вязкость композиции, способ-

Influence of mineral additives on the formation of a porous structure in liquid-glass granular heat-insulating materials 
ность композиции к удалению влаги при вспучивании, степень перестройки структуры материала при вспучивании. Поэтому эта работа посвящена изучению именно данных характеристик.

Вязкость ЖСК оценивалась с использованием вискозиметра В3-4 с диаметром сопла 4 мм (по времени истечения).

Количество влаги, удаляемой при вспучивании материала, рассчитывали по формуле

$$
\mathrm{W}=\frac{\mathrm{m}-\mathrm{m}_{1}}{\mathrm{~m}_{1}} \cdot 100
$$

где W - количество влаги, удаленной при вспучивании, \%; m - масса образца до вспучивания, г; $\mathrm{m}_{1}-$ масса вспученного образца, г.

Степень перестройки структуры материала при вспучивании определялась согласно методике расчета фазового состава дисперсного материала [7].

\section{Результаты и обсуждение}

Зернистые теплоизоляционные материалы получают двух видов: с диаметром зерен от 0,01 до 5 мм и более 5 мм. Для реализации этой цели применяли фильеры с двумя видами отверстий - 1 мм и 2,5 мм, соответственно. Для достижения необходимой вязкости композиции (времени истечения ЖСК через отверстие калиброванного размера), при которой наблюдается свободное каплепадение без забивания отверстий или же, наоборот, истечения сплошными струями, вводились различные количества минеральных наполнителей.

Влияние количества и типа наполнителя на вязкость композиций представлено на рис. 1.

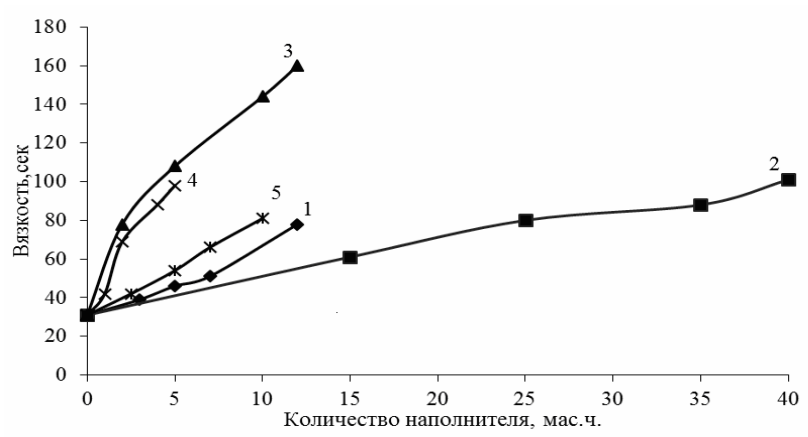

Рис. 1. Влияние типа и количества наполнителя на вязкость жидкостекольной композиции: 1 - каолин;

2 - доломитовая мука; 3 - оксид железа (III);

4 - оксид цинка; 5 - карбонат кальция
Как видно из рис. 1, наибольшими значениями вязкости обладают композиции с содержанием оксида железа(III) и доломита в качестве наполнителя, так как эти наполнители имеют большой удельный вес (для оксида железа

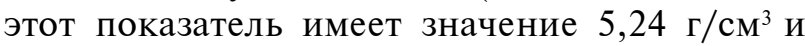

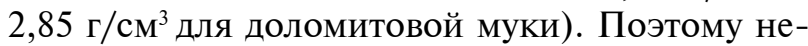
обходимо использовать более высокое их содержание для загущения композиции и достижения необходимой для пропускания через фильеру вязкости. Наполнители, которые имеют удельный вес меньше (удельный вес каолина и

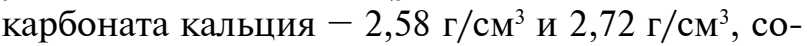
ответственно), вводятся в значительно меньшем количестве, поскольку они хорошо загущают композицию. В малом количестве вводится оксид цинка, так как избыточное его содержание в ЖСК приводит к преждевременному гелеобразованию смеси, и композицию невозможно пропустить через фильеру.

Так, вязкость композиций с оксидом железа(III) возрастает от 78 до 160 с (при 2 и 12 мас.ч добавки, соответственно) и от 61 до 101 с для доломита (при 15 и 40 мас.ч добавки, соответственно). Оптимальным количеством оксида цинка является 1,5 мас.ч, так как вязкость такой композиции составляет 69 с. Для свободного пропускания ЖСК через фильеру ее вязкость должна составлять 60-80 с (для использования фильер обоих типов 1 мм и 2,5 мм), так, например, вязкость композиций с содержанием наполнителя 3-12 мас.ч составляет 39-78 с.

Известно, что выпускаемое промышленностью жидкое стекло за счет содержащегося в нем нанодисперсного аморфного кремнезема при температурной обработке способно структурироваться с образованием пор, разделенных межпоровыми перегородками. Качество получаемой структуры непосредственно связано со способом удаления присутствующей в избыточном количестве (50-60\%) химически несвязанной воды. Неравномерное или с высокой скоростью ее удаление приводит к образованию крупнопористой, часто с межпоровыми «дырами», структуры. Эффективным способом создания твердой фазы в жидковязких композициях, является введение различных минеральных наполнителей. Эффект от их применения определяется контактным взаимодействием наполнителя со связующим: чем поверхность первого больше, тем меньшее его количество требуется для равномерного распределения жидкой фазы в смеси и стабилизации процесса удаления свободной воды. 
За кажущейся внешней простотой этого процесса скрываются весьма сложные проблемы технологического характера, обусловленные, прежде всего, высоким влагосодержанием самого жидкого стекла. Например, исходное натриевое жидкое стекло с плотностью 1450 кг $/ \mathrm{M}^{3}$ и модулем 3 содержит около 55 мас.\% жидкой фазы и 45 мас.\% твердой [8].

В зернистом материале, изготовленном из чистого жидкого стекла, содержание свободной не связанной воды составляет не менее $25 \%$. При добавлении минерального наполнителя, как было указано выше, количество твердой фазы в исходной ЖСК возрастает, следовательно, содержание свободной влаги падает. Но, так как эффективное порообразование происходит лишь при удалении связанной молекулярной воды, можно сделать вывод, что для получения вспученного гранулированного материала количество удаляемой влаги не должно быть менее $25 \%$.

Для всех видов наполнителей с увеличением его количества растет количество удаляемой при вспучивании воды. При малых количествах наполнителя происходит упрочнение межпоровых стенок в структуре гранулы - наполнитель служит каркасообразующим агентом, и удалению адсорбционной влаги препятствуют упрочненные стенки, в то время как свободная влага легко удаляется при комнатной температуре, и во вспучивании участвует только связанная, что положительно влияет и на получаемую пористую структуру, и на продолжительность процесса. Увеличенное количество минеральной добавки оказывает разупорядочивающее действие на макроструктуру материала, разрушая ее, как

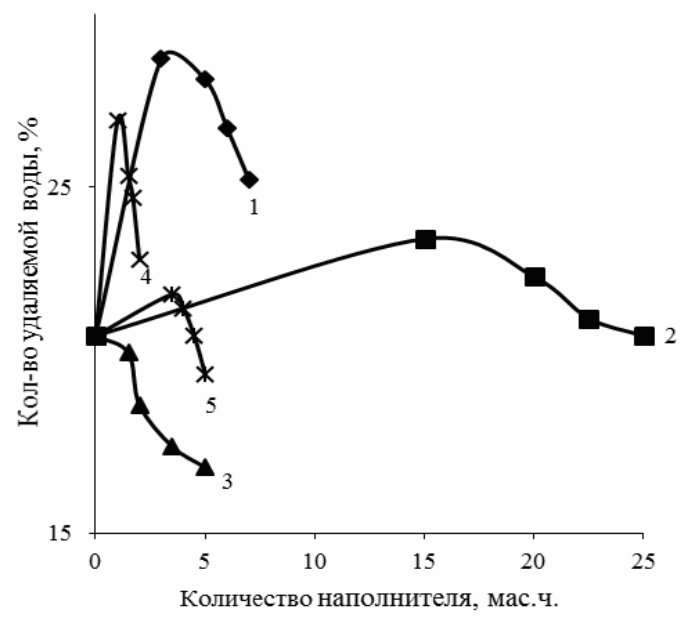

a

Рис. 2. Влияние типа и количества наполнителя на количество удаляемой при вспучивании воды: $1-$ каолин,

2 - доломитовая мука, 3 - оксид железа(III); 4 - оксид цинка, 5 - карбонат кальция (гранулы, получены пропусканием ЖСК через фильеру с диаметром отверстий: (а) 1 мм, (б) 2,5 мм) следствие, химически связанная влага переходит в свободное состояние и может удаляться даже при низких температурах нагрева.

Влияние типа и количества наполнителя на количество воды, удаляемой при вспучивании гранулированного материала, показано на рис. 2.

Получение гранулированного материала, имеющего после вспучивания равномерную пористость И низкую плотность, возможно при выполнении следующего условия: количество минерального наполнителя, достаточного для каплепадения на фильерах обоих типов, не должно превышать того уровня, при котором наблюдается разрушение структуры жидкого стекла и переход связанной воды в свободную. Кроме того, наполнитель не может применяться в таких количествах, при которых образуется чрезмерно высокая доля твердой фазы, так как вспученный материал будет иметь большую плотность.

Самыми низкими показателями количества воды, перешедшей в пар в процессе вспучивания, обладают гранулы с содержанием оксида железа(III) (при количестве добавки 1,5-5,0 мас.ч показатель составляет 20,2-16,9\% для материала, изготовленного на фильере 1 мм) и карбонатом кальция (при содержании добавки 3,55,0 мас.ч количество удаленной воды составляет 21,9-19,6\% при использовании фильеры 1 мм). Карбонат кальция является мелкодисперсным материалом, и, как указано выше, для достижения необходимых реологических характеристик исходной ЖСК, данный наполнитель применялся в малых количествах. Однако при указанном выше содержании карбоната кальция исходная

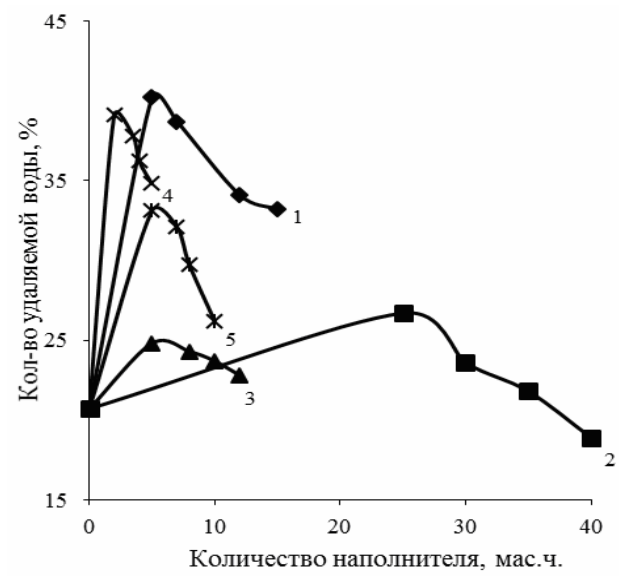

б 
ЖСК претерпевает такую модификацию, при которой количество образованной твердой фазы препятствует свободному порообразованию. Доломитовая мука является крупнодисперсным материалом, поэтому его содержание в исходной ЖСК высокое, однако это привело к разрушению коллоидной структуры жидкого стекла и переходу части молекулярной воды в свободную, вследствие чего был получен высокий показатель удаленной из материала воды. Применение же оксида железа способствует упрочнению внутреннего каркаса в грануле настолько, что образование пор практически невозможно, поэтому были получены низкие показатели количества удаленной воды.

Для гранулированного материала, содержащего оксид цинка и изготовленного на фильере 1 мм, показатели количества удаленной воды достаточно высокие - при увеличении содержания наполнителя от 1 до 2 мас.ч количество удаленной воды незначительно падает от 26,9 до 22,9\%, что свидетельствует о высокой вязкости исходной ЖСК вследствие коагуляции жидкого стекла наполнителем и образования твердой фазы, приведшей к наиболее полному выходу молекулярной воды во время вспучивания. Данный факт позволяет сделать вывод, что оксид цинка в целом является наиболее оптимальным наполнителем для приготовления ЖСК с высокой вспучивающейся способностью, а количество его должно составлять порядка 1,5 мас.ч, так как при 1 мас.ч вязкость композиции, как было показано выше, недостаточная, а при 2 мас.ч уже уменьшается количество удаляемой при вспучивании влаги.

Достаточно высокими показателями количества удаляемой влаги характеризуются вспученные гранулы с наполнителем каолин (для обоих типов фильер). Так, при вспучивании гранул, полученных на фильере 1 мм, было удалена вода в количестве $28,7-25,2 \%$ при содержании добавки 3-7 мас.ч. Каолин способствует образованию не только прочной внешней корочки на поверхности гранул после сушки материала на воздухе, но и упрочненного внутреннего каркаса, препятствующего образованию крупных пор и интенсивному испарению связанной воды.

В целом, применение фильеры с диаметром отверстий 2,5 мм обусловливает применение больших количеств наполнителей для придания необходимой вязкости ЖСК, чтобы наблюдалось каплепадение, а не свободное истечение через фильеру. Большие количества на- полнителей, независимо от их дисперсности, привели к процессам разрушения структуры ЖС и переходу молекулярной влаги в свободную, поэтому были получены такие высокие показатели потери воды в процессе вспучивания.

На основании результатов исследований можно сделать вывод, что фильера с диаметрами отверстий 2,5 мм не приемлема для изготовления гранулированного материала с низкой плотностью, о чем свидетельствуют и опытные данные (к примеру, плотность материала с содержанием карбоната кальция в количестве 7 мас.ч, изготовленного на фильере 2,5 мм, составляет $\left.0,56 г / \mathrm{cm}^{3}\right)$. Поэтому дальнейшие исследования проводились с материалом, изготовленным на 1-миллиметровой фильере.

С целью определения интенсивности преобразования исследуемых материалов в процессе вспучивания и определения характеристик, указывающих на технологичность той или иной ЖСК, был проведен расчет фазового состава дисперсного материала.

Процесс трансформации структур является основой технологии получения различных материалов и изделий на основе дисперсных систем. Для управления технологическим процессом перестройки структур на каждой технологической стадии необходимо знать состав и свойства структур, а также иметь такие оценочные параметры, которые позволяют оценивать перестройку этих структур независимо от их состава и свойств. Таким требованиям удовлетворяют объемные фазовые характеристики структур и, в первую очередь, объемное содержание твердой фазы. Основным преимуществом использования объемных фазовых характеристик является то, что сумма объемных долей твердой $\left(\mathrm{K}_{\mathrm{T}}\right)$, жидкой $\left(\mathrm{K}_{ж}\right)$ и газообразной $\left(\mathrm{K}_{\Gamma}\right)$ фаз дисперсной системы или структуры равна единице независимо от вида структуры и вида внешнего энергетического воздействия на систему [7]:

$\mathrm{K}_{\mathrm{T}}+\mathrm{K}_{\text {}}+\mathrm{K}_{\mathrm{\Gamma}}=1$.

Если используется влажный материал, то сначала определяется кажущаяся плотность влажного материала $\rho_{\text {вл }}=\mathrm{m}_{\text {вл }} / \mathrm{V}$, а затем рассчитывают кажущуюся плотность сухого материала:

$\rho_{\mathrm{c}}=\rho_{\text {вл }} /\left(1+\mathrm{W}_{\mathrm{a}}\right), \quad$ г $/ \mathrm{cm}^{3}$,

где $\mathrm{W}_{\mathrm{a}}$ - абсолютная влажность материала, отн. ед. 
Объемная доля твердой фазы определяется из отношения кажущейся плотности образца к истинной плотности материала:

$\kappa_{\text {т }}=\rho_{\mathrm{c}} / \rho_{\text {и }}$, отн.ед.

Объемная влажность $\mathrm{W}_{\text {оь }}$ или объемная доля жидкой фазы определяется по формуле

$\mathrm{W}_{\text {об }}=\mathrm{K}_{\text {ж }}=\mathrm{W}_{\mathrm{a}} \cdot \rho_{\mathrm{c}}$, отн.ед.

Объемное содержание газовой фазы или пористость образца определяется по разности:

$\mathrm{K}_{\mathrm{r}}=1-\left(\mathrm{K}_{\mathrm{T}}+\mathrm{K}_{\text {ж}}\right)$, отн.ед.

Для сухого, сыпучего, т.е. двухфазного материала, баланс объемных долей имеет вид: $\mathrm{K}_{\mathrm{T}}+\mathrm{K}_{\mathrm{\Gamma}}=1$ и из этого выражения определяется объемная доля газовой фазы $\mathrm{K}_{\Gamma}$ при известном значении $\mathrm{K}_{\mathrm{T}}$.

В математическом виде для процесса поризации жидкостекольной композиции закон записывается следующим образом:

$\mathrm{K}_{\mathrm{T}_{\mathrm{H}}}+\mathrm{K}_{\text {жи }_{\mathrm{H}}}=\mathrm{K}_{\mathrm{T}_{\mathrm{i}}}+\mathrm{K}_{\varkappa_{\mathrm{i}}}+\mathrm{K}_{\mathrm{r}_{\mathrm{i}}}=\ldots=\mathrm{K}_{\mathrm{T}_{\mathrm{K}}}+\mathrm{K}_{\mathrm{\Gamma}_{\mathrm{K}}}$,

где $\mathrm{K}_{\mathrm{r}}, \mathrm{K}_{ж}, \mathrm{~K}_{\mathrm{r}}$ - объемное содержание твердой, жидкой и газообразной фаз в системе на соответствующей технологической стадии. Для данного процесса закон можно записать:

$\mathrm{K}_{\mathrm{T}_{\mathrm{H}}}+\mathrm{K}_{ж_{\mathrm{H}}}=\mathrm{K}_{\mathrm{T}_{\mathrm{K}}}+\mathrm{K}_{\mathrm{T}_{\mathrm{K}}}=1$

На основании этого закона можно получить параметр (n), характеризующий интенсивность процессов структурообразования в динамичных системах. Он показывает относительное изменение соотношения объемной концентрации твердой фазы и свободного порового пространства, при переходе дисперсной системы из одного состояния в другое, под влиянием внешнего энергетического воздействия (химического, механического или теплового.) Величину n можно определить из соотношения:

$\mathrm{K}_{\mathrm{T}_{2}} /\left(1-\mathrm{K}_{\mathrm{T}_{2}}\right)=\mathrm{n} \cdot \mathrm{K}_{\mathrm{T}_{1}} /\left(1-\mathrm{K}_{\mathrm{T}_{1}}\right)$,

где $\mathrm{K}_{\mathrm{r1}}, \mathrm{K}_{\mathrm{r} 2}$ - объемная доля твердой фазы в начале и конце поризации системы, соответственно.

Если в системе не происходит никаких изменений, то $\mathrm{n}=1$. Уменьшение объема системы характеризуется $\mathrm{n}>1$, а при ее увеличении (поризация) $\mathrm{n}<1$. Если нормировать изменение параметра $n$ в пределах (0-1), то при поризации

Данные расчета фазового состава зернистого теплоизоляционного материала

\begin{tabular}{|c|c|c|c|c|c|c|c|c|c|c|c|c|}
\hline \multirow{2}{*}{\multicolumn{2}{|c|}{ Наполнитель }} & \multicolumn{5}{|c|}{ Влажный материал } & \multicolumn{4}{|c|}{ Вспученный материал } & \multirow[b]{2}{*}{$\alpha_{n}$} & \\
\hline & & $\mathrm{W}_{\text {абс (после сушки) }}$ & $\rho_{1 \text { каж. }}^{\text {в }}$ & $\rho_{1 \text { ист. }}^{\text {в. }}$ & $\mathrm{K}_{\mathrm{T} 1}$ & $K_{ж}$ & $\rho_{2 \text { каж) }}^{\text {cyx }}$ & & $\mathrm{K}_{\mathrm{T} 2}$ & $\mathrm{~K}_{\Gamma}$ & & \\
\hline \multicolumn{2}{|c|}{ Без наполнителя } & 0,207 & 2,02 & 2,44 & 0,83 & 0,17 & 0,03 & 0,18 & 0,17 & 0,83 & 0,96 & 0,04 \\
\hline \multirow{4}{*}{ Каолин } & 3 мас.ч & 0,287 & 1,17 & 1,51 & 0,77 & 0,23 & 0,29 & 0,43 & 0,67 & 0,33 & 0,39 & 0,61 \\
\hline & 5 мас.ч & 0,281 & 1,26 & 1,62 & 0,78 & 0,22 & 0,32 & 0,47 & 0,69 & 0,31 & 0,37 & 0,63 \\
\hline & 6 мас.ч & 0,267 & 1,4 & 1,78 & 0,8 & 0,2 & 0,346 & 0,48 & 0,72 & 0,28 & 0,36 & 0,64 \\
\hline & 7 мас.ч & 0,252 & 1,44 & 1,8 & 0,8 & 0,2 & 0,36 & 0,49 & 0,73 & 0,27 & 0,32 & 0,68 \\
\hline \multirow{4}{*}{$\begin{array}{l}\text { Доломитовая } \\
\text { мука }\end{array}$} & 15 мас.ч & 0,235 & 1,41 & 1,74 & 0,81 & 0,19 & 0,42 & 0,54 & 0,78 & 0,22 & 0,17 & 0,83 \\
\hline & 201 & 0,224 & 1,46 & 1,79 & 0,82 & 0,18 & 0,55 & 0,7 & 0,79 & 0,21 & 0,18 & 0,82 \\
\hline & 22,5 мас.ч & 0,212 & 1,53 & 1,86 & 0,82 & 0,18 & 0,565 & 0,73 & 0,77 & 0,23 & 0,22 & 0,78 \\
\hline & $25 \mathrm{k}$ & 0,207 & 2,22 & 2,68 & 0,83 & 0,17 & 0,55 & 0,72 & 0,76 & 0,24 & 0,35 & 0,65 \\
\hline \multirow{4}{*}{ Оксид железа(III) } & 1,5 мас.ч & 0,202 & 0,95 & 1,14 & 0,83 & 0,17 & 0,49 & 0,61 & 0,8 & 0,2 & 0,18 & 0,82 \\
\hline & 2 мас.ч & 0,187 & 1,33 & 1,58 & 0,84 & 0,16 & 0,54 & 0,68 & 0,85 & 0,21 & 0,2 & 0,8 \\
\hline & 3,5 мас.ч & 0,175 & 1,41 & 1,66 & 0,85 & 0,15 & 0,556 & 0,68 & 0,82 & 0,18 & 0,2 & 0,8 \\
\hline & 5 мас.ч & 0,169 & 1,46 & 1,71 & 0,85 & 0,15 & 0,58 & 0,7 & 0,83 & 0,17 & 0,14 & 0,86 \\
\hline \multirow{4}{*}{ Оксид цинка } & 1 мас.ч & 0,269 & 0,97 & 1,23 & 0,77 & 0,23 & 0,19 & 0,35 & 0,54 & 0,46 & 0,65 & 0,35 \\
\hline & 1,5 мас.ч & 0,253 & 1,1 & 1,37 & 0,8 & 0,2 & 0,23 & 0,39 & 0,59 & 0,41 & 0,64 & 0,36 \\
\hline & 1,7 мас.ч & 247 & 1,22 & 1,52 & 0,8 & 0,2 & 0,236 & 0,38 & 0,62 & 0,38 & 0,59 & 0,41 \\
\hline & 2 мас & 229 & 1,36 & 1,67 & 0,81 & 0,19 & 0,24 & 0,37 & 0,65 & 0,35 & 0,56 & 0,44 \\
\hline \multirow{4}{*}{ Карбонат кальция } & 3,5 мас.ч & 0,219 & 1,47 & 1,79 & 0,82 & 0,18 & 0,37 & 0,51 & 0,73 & 0,27 & 0,41 & 0,59 \\
\hline & 4 мас.ч & 0,215 & 1,56 & 1,89 & 0,82 & 0,18 & 0,39 & 0,53 & 0,74 & 0,26 & 0,37 & 0,63 \\
\hline & 4,5 мас.ч & 0,207 & 1,63 & 1,97 & 0,83 & 0,17 & 0,4 & 0,53 & 0,75 & 0,25 & 0,39 & 0,61 \\
\hline & 5 мас.ч & 0,196 & 1,74 & 2,08 & 0,84 & 0,16 & 0,43 & 0,55 & 0,78 & 0,22 & 0,32 & 0,68 \\
\hline
\end{tabular}

Influence of mineral additives on the formation of a porous structure in liquid-glass granular heat-insulating materials 
степень перестройки структуры $\left(\alpha_{n}\right)$ материала можно определить по соотношению:

$$
\alpha_{\mathrm{n}}=\left(1 / \mathrm{n}_{\mathrm{i}}-1\right) /\left(1 / \mathrm{n}_{\mathrm{i}}\right)
$$

где $1 / \mathrm{n}_{\mathrm{i}}-$ вспучиваемость материала в процессе или в конце воздействия на дисперсную систему; $1 / \mathrm{n}_{\mathrm{i}}=\mathrm{V}_{2} / \mathrm{V}_{1}$; где $\mathrm{V}_{2}$ и $\mathrm{V}_{1}$ - объем системы в конечном и начальном состояниях, соответственно, $\mathrm{cm}^{3}$.

Из последней зависимости видно, что чем большим значением параметра $\alpha_{\mathrm{n}}$ характеризуется переход системы из начального состояния в конечное, тем интенсивнее протекают процессы поризации данной системы и перестройки структуры материала. Кроме того, из этих формул следует важный технологический вывод: чем выше объемная концентрация твердой фазы в исходном материале, тем интенсивнее происходит процесс поризации [7].

Расчеты фазового состава зернистого материала приведены в таблице.

Зависимости степени перестройки структуры $\alpha_{n}$ от количества и вида применяемого наполнителя приведены на рис. 3.

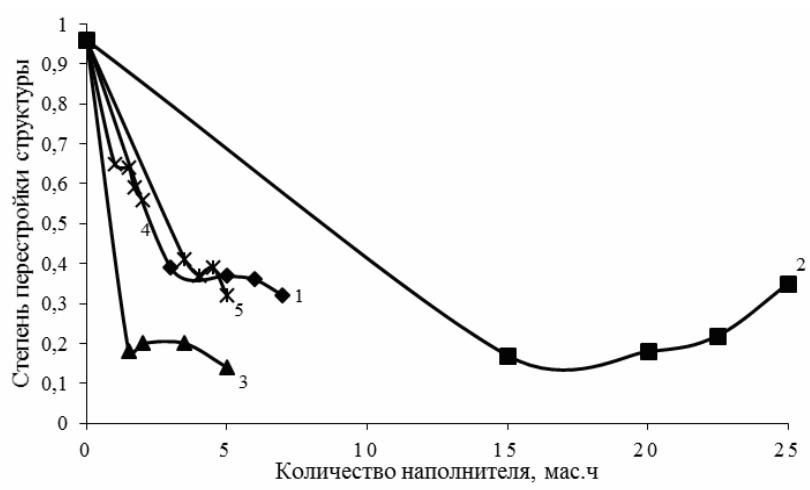

Рис. 3. Влияние типа и количества наполнителя на степень перестройки структуры: 1 - каолин;

2 - доломит; 3 - оксид железа(III); 4 - оксид цинка; 5 - карбонат кальция

Наивысшее значение параметра степени перестройки $\alpha_{\mathrm{n}}$ характеризует материал, у которого после вспучивания объем увеличился больше всего, то есть было применено такое оптимальное количество наполнителя, при котором жидкостекольная композиция имеет вязкость, достаточную для максимального увеличения объема. Как видно из рис. 3 , чрезмерное увеличение количества наполнителя придает исходной смеси настолько большую вязкость, что образование большого количества пор невозможно. Малое содержание наполнителя не придает композиции достаточной стабильности, при которой образовавшиеся поры сохраняют прочность.

На основании полученных данных установлено:

1. Для получения гранулированного теплоизоляционного материала применение оксида железа (III) нецелесообразно, так как такие гранулы имеют низкую поризационную способность. Не зависимо от применяемого количества данного наполнителя, значения параметра структурообразования $\mathrm{n}$ не опускаются ниже значения 0,8 , что говорит о низкой поризационной способности исходной ЖСК. Использование оксида железа(III) привело к образованию прочного внутреннего каркаса гранулы, который в процессе вспучивания препятствовал свободному образованию пор, то есть давление паров воды внутри образующихся пустот недостаточно для преодоления сил поверхностного натяжения. Очевидно, что оксид железа(III) не может быть использован в качестве наполнителя при производстве зернистых теплоизоляционных материалов.

2. В отличие от процессов порообразования с применением других наполнителей, увеличение количества доломитовой муки вызвало снижение показателя n. Так, доломит является грубодисперсным наполнителем, и для придания необходимых реологических характеристик исходной ЖСК его использовали в больших количествах. Данный факт вызвал связывание диполей свободной воды на поверхности частиц доломита, что привело к разжижению жидкого стекла и разрушению его структуры. В итоге с увеличением количества доломита способность ЖСК к вспучиванию за счет испарения связанной воды упала, и наблюдалось уменьшение показателя параметра структурообразования.

3. Материал с содержанием карбоната кальция в качестве минерального наполнителя характеризуется достаточно высокой способностью к вспучиванию, так, степень перестройки структуры составляет $0,41-0,32$. Однако, согласно данным таблицы 1 , полученный материал имеет высокую плотность $\left(0,37-0,42\right.$ г/см $\left.{ }^{3}\right)$, так как мел вызывает увеличение количества твердой фазы в процессе приготовления ЖСК, и готовый материал характеризуется низким содержанием газовой фазы (0,27-0,22 усл.ед.).

4. При использовании каолина в качестве минерального наполнителя был получен мате- 
риал со средними показателями параметра структурообразования, которые практически равны для всех количеств каолина и составляют 0,610,68. Так как каолин является глинистым материалом с низкой адсорбционной способностью, он практически полностью инертен к жидкому стеклу, и в процессе приготовления ЖСК вызывает увеличение содержания твердой фазы только за счет своей мелкой дисперсности, и, как следствие, большого количества частиц. При этом более интенсивному вспучиванию, чем в случае ЖСК с содержанием оксида цинка, препятствуют упрочненные межпоровые стенки.

5. Наиболее низким значением параметра структурообразования $(0,35-0,44)$ и высоким значением степени перестройки структуры $(0,65-0,56)$ в сочетании с низкой плотностью

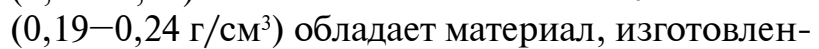
ный с использованием оксида цинка в качестве наполнителя. Этот наполнитель позволяет получить ЖСК с наиболее высокой способностью к вспучиванию, так как за счет мелкодисперсности и большой площади смачивания исходная ЖСК имеет вязкость, достаточную для образования закрытых мелких пор.

\section{Выводы}

На основании проведенных исследований было определено, что применение наполнителя оксид цинка в количестве 1,5 мас.ч на 100 мас.ч жидкого стекла при изготовлении гранулированного материала является наиболее оптимальным, так как данный наполнитель придает вспученному грануляту низкий показатель плотности, а также высокую способность к вспучиванию, о чем говорит высокое значение степени перестройки структуры $(0,64)$.

Такой гранулированный материал на основе жидкого стекла и оксида цинка может применяться в качестве насыпной теплоизоляции, а так же в качестве зернистого наполнителя при производстве блочных теплоизоляционных материалов.

\section{СПИСОК ЛИТЕРАТУРЫ}

1. Papadopoulus A.M. State of the art in thermal insulation materials and aims for future developments // Energy Build. 2005. - Vol.37 - P.77-86.

2. Composition, synthesis and properties of insulation foam glass obtained from packing glass waste / Lakov L., Toncheva K., Staneva A., Simeonova T., Ilcheva Z. // J. Chem. Technol. Metall. - 2013. - Vol.48. - P.125-129.

3. Mizuriaev S.A., Zhigulina A.Yu., Solopova G. Production technology of waterproof porous aggregates based on alkali silicate and non-bloating clay for concrete of general usage // Proced.
Eng. - 2015. - Vol.111. - P.540-544.

4. Пат. 9018139 США, МКИ В2 С03С11/00, С09К8/ 03, C03B19/10. Method for producing expanded glass granules and the use thereof / R. Tschiersch, M. Stiebert, A. Kuhne, J. Driesner (США). - Заявл. 19.03.2014; Опубл. 28.04.2015; НКИ 290/45. -4 c.

5. Preparation of heat insulation material from water glass modified with sodium chloride / Denisov D.Yu., Kulikov V.A., Abdrakhimov V.Z., Kovkov I.V., Vdovina E.V., Mikheev V.A., Zhuravel' L.V., Roshchupkina I.Yu. // Refract. Ind. Ceram. 2012. - Vol.52. - P.331-334.

6. Yakovlev G., Kodolov V. Intumescent fireproof coating based on water glass // Int. J. Polymer. Mater. Polymer. Biomater. - 2000. - Vol.47. - P.107-115.

7. Лотов В.А., Кутугин В.А. Формирование пористой структуры пеносиликатов на основе жидкостекольных композицій // Стекло и керамика - 2008. - Т.65. - №1. - С.610.

8. Vail J.G. Soluble silicates - their properties and uses. New York: Chemistry. Reynolds. - 1952. - Vol.1. - P.112-117.

Поступила в редакцию 22.10.2018

\section{ВПЛИВ МІНЕРАЛЬНИХ ДОБАВОК НА ПРОЦЕС ФОРМУВАННЯ ПОРИСТОЇ СТРУКТУРИ РІДКОСКЛЯНИХ ЗЕРНИСТИХ ТЕПЛОІЗОЛЯЦІЙНИХ МАТЕРІАЛІВ}

\section{T.E. Римар}

Вивчено вплив мінеральних добавок на процес формування пористої структури рідкоскляних зернистих теплоізоляційних матеріалів. Для регулювання реологічних характеристик сировинної суміші і експлуатаційних властивостей спучених матеріалів при виробництві зернистих утеплювачів на основі рідкоскляних композицій (РСК) вводилися тонкомолоті мінеральні наповнювачі: каолін, доломітове борошно, ферум(III) оксид, цинк оксид, кальцій карбонат. Встановлено, що застосування наповнювача цинк оксиду в кількості 1,5 мас.ч на 100 мас.ч рідкого скла при виготовленні гранульованого матеріалу є найбільш оптимальним, оскільки даний наповнювач надає спученому грануляту низький показник щільності, а також високу здатність до спучування, про що свідчить високе значення ступеня перебудови структури $(0,64)$. Суворо дозований вміст иинк оксиду дозволяє спростити гранулювання вихідної РСК через фільєрну пластину, так як швидкість витікання иієї суміші в порівнянні з чистим рідким склом (31 с) збільшилася вдвічі (69 с). При цьому поризаційна здатність композиції не падає, оскільки кількість вилученої при спученні вологи становить 25,3\%, що вище, ніжк кількість вилученої вологи при спученні гранул, виготовлених тільки з рідкого скла $(20,7 \%)$. Таким чином, вміст цинк оксиду в РСК у кількості 1,5 мас.ч приводить до створення в структурі гранули достатньої кількості твердої фази без руйнування структури молекули рідкого скла і переходу зв язаної води в вільну.

Ключові слова: мінеральні добавки, наповнювачі, зернистий теплоізоляційний матеріал, рідкоскляні композиції, пориста структура, спучування, в'язкість, фазовий склад. 


\section{INFLUENCE OF MINERAL ADDITIVES ON THE FORMATION OF A POROUS STRUCTURE IN LIQUID- GLASS GRANULAR HEAT-INSULATING MATERIALS}

\section{T.E. Rymar}

Volodymyr Dahl East Ukrainian National University, Severodonetsk, Ukraine

\section{e-mail: rymartatyana1975@gmail.com}

The effect of mineral additives on the formation of a porous structure in liquid-glass granular heat-insulating materials was investigated. In order to control rheological properties of the raw mixture and performance properties of foamed materials, fined mineral fillers (kaolin, dolomite powder, iron(III) oxide, zinc oxide, and calcium carbonate) were introduced during the production of granular insulators on the basis of the liquid-glass compositions ( $L G C)$. It was found that the use of zinc oxide as a filler in an amount of 1.5 weight parts per 100 weight parts of liquid glass in the production of granular materials is the most acceptable, since this filler imparts low density and high foaming ability to the foamed granulate, which is confirmed by a high degree of the structure restructuring (0.64). Strictly dosed content of zinc oxide allows simplifying the granulation of the original LGC through the bushing plate, since the flow rate of this mixture has doubled $(69 \mathrm{~s})$ in comparison with pure liquid glass (31 s). In addition to that, the porosity of the composition does not decrease as the amount of the removed moisture is $25.3 \%$ which is higher than that removed during foaming of granules prepared only using liquid glass (20.7\%). Thus, 1.5 weight parts of zinc oxide in the $L G C$ resulted in the formation of a sufficient amount of a solid phase in the granule structure without destroying the structure of the liquid glass molecule and transition of bound water into free water.

Keywords: mineral additives; filler; granular heat-insulating material; liquid-glass composition; porous structure; foaming; viscosity; phase composition.

\section{REFERENCES}

1. Papadopoulus A.M. State of the art in thermal insulation materials and aims for future developments. Energy and Buildings, 2005, vol. 37 , pp. 77-86.

2. Lakov L., Toncheva K., Staneva A., Simeonova T. Ilcheva Z. Composition, synthesis and properties of insulation foam glass obtained from packing glass waste. Journal of Chemical Technology and Metallurgy, 2013, vol. 48, pp. 125-129.

3. Mizuriaev S.A., Zhigulina A.Yu., Solopova G.S. Production technology of waterproof porous aggregates based on alkali silicate and non-bloating clay for concrete of general usage. Procedia Engineering, 2015, vol. 111, pp. 540-544.

4. Tschiersch R., Stiebert M., Kuhne A., Driesner J., Method for producing expanded glass granules and the use thereof. Patent US, no. 9018139, 2015.

5. Denisov D.Yu., Kulikov V.A., Abdrakhimov V.Z., Kovkov I.V., Vdovina E.V., Mikheev V.A., Zhuravel' L.V., Roshchupkina I.Yu. Preparation of heat insulation material from water glass modified with sodium chloride. Refractories and Industrial Ceramics, 2012, vol. 52, pp. 331-334.

6. Yakovlev G., Kodolov V. Intumescent fireproof coating based on water glass. International Journal of Polymeric Materials and Polymeric Biomaterials, 2000, vol. 47, pp. 107-115.

7. Lotov V.A., Kutugin V.A. Formation of a porous structure of foam silicates based on liquid-glass compositions. Glass and Ceramics, 2008, vol. 65, pp. 6-10.

8. Vail J.G., Soluble silicates - their properties and uses, vol. 1. Chemistry. Reynolds, New York, 1952. 